\title{
APOYOS PARA MAÍZ EN MÉXICO: EL PROGRAMA GUBERNAMENTAL DE AGRICULTURA POR CONTRATO
}

\author{
F. Echánove Huacuja \\ Instituto de Geografía, Universidad Nacional Autónoma de México \\ Avenida Universidad 3000, México DF. 04510 \\ flavia2451@gmail.com
}

\begin{abstract}
Resumen: Desde hace poco más de una década, el gobierno mexicano ha venido aplicando dos programas de subsidios para proteger a productores y empresas compradoras de granos de los riesgos de las fluctuaciones de los precios de esos bienes a nivel internacional. Este tipo de apoyos, plasmados en los programas denominados "agricultura por contrato" y "coberturas de precios", son el objeto de la investigación. Se estudian sus características centrales, así como sus limitantes y efectos, tanto en los productores de maíz del estado de Puebla, como en las firmas pecuarias compradoras de dicho grano. Entre los hallazgos de la investigación figura el hecho de que si bien los programas ofrecen importantes ventajas a los participantes, son frecuentes los incumplimientos de contratos debidos a desastres climáticos, relación de precios (internacionales vs. mercado libre) y evolución del tipo de cambio. Se reseña también el carácter regresivo de los apoyos y su concentración geográfica. La necesidad de reorientar la política de subsidios agrícolas en México es una de las conclusiones del artículo, señalando las posibles alternativas.
\end{abstract}

Palabras clave: subsidios, política agrícola, agricultura por contrato, alimentos animales, México.

\begin{abstract}
For more than one decade, the Mexican government implemented two subsidy programs (contract farming and price hedging) to protect grain farmers and firms from the risks related to international price fluctuations. In this article, we analyze the characteristics and limitations of these two programs as well as its effects on maize producers and feed firms in the state of Puebla, Mexico. Among our findings is the fact that
\end{abstract}

Recibido: 28-04-2015. Aceptado: 20-09-2015. 
while these programs offer important advantages to the participants, the buyer-seller contracts are often breach as a result of climatic disasters, differences in relative prices (international vs. open market) and changes in international exchange rates. The studied programs are regressive and subsidies are concentrated geographically. We reflect on the need to reorient the government support to the agricultural sector in Mexico.

Keywords: subsidies, agricultural policy, contract farming, animal feed, Mexico.

\section{Introducción: la reorientación de la política agrícola mexicana}

A raíz de la crisis de la deuda externa de México en 1982, la política agrícola y alimentaria que se había caracterizado por un elevado grado de regulación e intervencionismo gubernamental, inicia un proceso de cambio como efecto de la aplicación de programas de ajuste estructural de corte neoliberal. Los tres ejes centrales de este proceso han sido el redimensionamiento del Estado, la liberalización comercial y la reforma a la legislación agraria (Appendini, 2014; Echánove, 2013a; Yuñez, 2008). Así, durante los años ochenta del siglo pasado inicia la desaparición de empresas paraestatales y la consiguiente eliminación o reducción de diversos subsidios para los productores agropecuarios (al crédito, adquisición de insumos, aseguramiento, almacenamiento, etc.); se suprimen los precios de garantía (precios mínimos de compra) para la mayoría de los granos; arranca la liberalización del mercado para los productos agrícolas mediante la adhesión de México al GATT (Acuerdo General sobre Aranceles y Comercio) (1986); inicia el abandono del gobierno en extensionismo e investigación, y se desploma la inversión pública en el sector. Durante los años noventa, se da continuidad a varias de esas medidas, a las que se añaden la profundización de la apertura comercial mediante la incorporación de México al TLCAN (1994) y, en 1995, la eliminación de los precios de garantía de dos granos muy relevantes en la dieta mexicana: maíz y frijol. Igualmente se abandona la política de control de precios al consumidor de los alimentos básicos, entre los que figura la tortilla, cuyo precio se liberaliza en 1999.

Sin embargo, todo lo anterior no ha significado el fin de la intervención gubernamental, ni de su política de subsidios a la producción y el mercado doméstico agrícola, sino un cambio en el grado y amplitud en el que lo hacía, así como en su enfoque e instrumentos, sobre todo en el caso de los granos, que tradicionalmente han sido los bienes con mayor regulación oficial. A partir de mediados de los noventa, los apoyos del gobierno se consolidan en programas que se centran en tres rubros principales: pagos directos a los productores, adquisición de infraestructura y equipo productivo, y apoyos a la comercialización. Los primeros de ellos se contienen en el programa PROAGRO Productivo, el más relevante en cuanto a número de productores apoyados y 
presupuesto asignado, dirigido a todo tipo de productor, incluyendo los de autoconsumo. En contraste, los otros subsidios, plasmados en los programas actualmente denominados Apoyos a la Inversión en Equipamiento e Infraestructura, y Prevención y Manejo de Riesgos, están dirigidos a productores comerciales, beneficiando mayoritariamente a los que cuentan con cierto grado de capitalización y organización.

Los apoyos del gobierno a la comercialización de granos empezaron a adquirir relevancia a partir de 1995, pero solo hasta 2003 se empieza a aplicar una política integral que en la última década se ha centrado en el otorgamiento de subsidios a productores y compradores de granos para protegerse de los riesgos de mercado, particularmente de las fluctuaciones de los precios internacionales. El programa mediante el cual se proporcionan dichos subsidios se denomina "agricultura por contrato" (AC), y son los apoyos gubernamentales que mayor dinamismo han presentado en los últimos años. Sin embargo, y a pesar de su importancia, son pocos los académicos que los han estudiado (véase Appendini, 2014; Echánove, 2013b, 2009; Lence, 2012; Fox y Haight, 2010; Steffen y Echánove, 2005), por lo cual resulta relevante que dichos apoyos constituyan nuestro objeto de estudio. Por ello, analizaremos en este artículo las características del mencionado programa, sus limitantes o vulnerabilidades, y sus efectos en los productores y empresas involucradas. Elegimos como caso de estudio el maíz blanco producido en el estado de Puebla, no solo porque conforma el principal grano producido en México y un buen ejemplo para estudiar la AC, sino porque aporta conocimientos sobre cómo los subsidios gubernamentales influyen en el destino o mercado de los productos agrícolas.

La metodología utilizada en la investigación incluyó recopilación de información estadística y hemerográfica, observación participante, y la realización de 45 entrevistas directas a los diversos actores que intervienen en la cadena producción-consumo del maíz de Puebla, como son productores y sus organizaciones, empresas comercializadoras, firmas pecuarias compradoras del grano y funcionarios gubernamentales. Esto, con el objetivo de conocer directamente de dichos agentes su apreciación sobre el programa de AC y sus experiencias en torno a los efectos (positivos y/o negativos) de estos apoyos. En el segundo apartado proporcionaremos un breve marco conceptual sobre la AC y su proceso de expansión, mientras que en el tercero y cuarto reseñaremos la relevancia de la importación de maíz amarillo en la dependencia alimentaria de México y el papel jugado por la industria de alimentos animales. En un quinto apartado se describirá la producción de maíz bajo contrato de Puebla y, en un sexto, se analizarán las características, importancia y estrategias del sector pecuario de Puebla, para en un séptimo reseñar el funcionamiento y vulnerabilidades del programa. Finalmente, se presentan las reflexiones finales de la investigación. 


\section{Agricultura por Contrato: un acuerdo en expansión}

La "agricultura por contrato" (AC), constituye una forma de "coordinación vertical" de los agro-negocios, al mismo tiempo que un mecanismo de abasto que se ubica entre las compras hechas en el mercado libre y la producción proveniente de tierras propias o rentadas ("integración vertical") (CEPAL/GTZ/FAO, 1998: 45). El sistema de AC implica la existencia de acuerdos orales o escritos entre los productores directos y toda una gama de agentes (mayoristas, industrias procesadoras, comerciantes detallistas, empacadores, organizaciones de productores, empresas públicas, etc.), en los cuales quedan regulados diversos aspectos de la producción y comercialización de productos agrícolas. A nivel mundial, el tipo y grado de control sobre el proceso productivo es muy variable, siendo los casos más extremos los que se dan en la producción de hortalizas para procesamiento industrial, y en la cría y engorda de aves y puercos, mientras que el sector con menos control es el productor de granos o cereales (Raynolds, 2000: 441).

La AC ha sido definida como una constelación de relaciones institucionales y productivas, y una de las estrategias de la industrialización y reestructuración de la agricultura a nivel mundial. Aunque la AC no es un fenómeno nuevo, diversos autores han dado cuenta de su acelerado proceso de expansión durante las últimas décadas (Singh, 2003; Raynolds, 2002; Gwynne, 2000; Little y Dolan, 2000; Lawerence, 1999; Vellema, 1999; McKenna, et. al. 1999; Grossman, 1998; White, 1997; Morvaridi, 1995). De acuerdo a Watts (1994), a fines del siglo pasado la AC se había convertido en parte integral de la industria alimentaria y de fibras en Europa Occidental, Norteamérica y Japón, país éste donde la cuarta parte del arroz era producido bajo contrato. Para 1998, una tercera parte del valor de la producción procedente de los granjeros de Estados Unidos era obtenida mediante acuerdos contractuales, siendo el sector ganadero el más relevante (95\% del valor de las aves de engorda; $43 \%$ de los cerdos y $55 \%$ de los productos lácteos). Sin embargo, en ese país la AC también tenía gran importancia en la producción de frutas, vegetales y algodón, siendo el sector de granos donde ese esquema era menos común, no obstante lo cual se aplicaba en el 13\% de la producción de maíz y el 12\% de la soja, granos que en su mayoría se destinan a la elaboración de alimentos animales (Perry y Banker, 2000: 52).

De acuerdo al USDA (1997), dicho régimen contractual les permite a las firmas procesadoras de alimentos un mayor control sobre la calidad y tiempos de entrega de los productos que requieren; mejorar su respuesta ante los cambios del mercado y alcanzar una mayor expansión y diversificación de sus operaciones, ventajas a las que Raynolds (1997) añade la de proporcionar a las firmas una mayor movilidad geográfica.

En los países del Tercer Mundo, la AC se ha expandido notablemente durante las últimas décadas, en gran medida vinculada al dinamismo de las exportaciones de los productos denominados no tradicionales, entre los que figuran diversas frutas y hortalizas, principalmente para exportación. En este sector productivo, el control sobre el proceso 
productivo por parte de las firmas compradoras es relevante, dada la exigencia de cumplir con ciertos estándares de calidad (textura, fragancia, color, peso y forma), lo cual implica constante asesoría técnica a los productores, quienes ven reducida la toma de decisiones propias (Dolan, 2001). En México, además del sector hortofrutícola, la AC es muy común en la producción de tabaco, caña de azúcar, y aves y puercos de engorda. En el caso de los granos, los contratos directos entre productores individuales o sus organizaciones y las firmas compradoras, han sido frecuentes en la producción de cebada, semillas y ciertas variedades de trigo desde hace varias décadas. Sin embargo, lo novedoso a partir de 2003, ha sido la implementación por parte del gobierno mexicano de un programa denominado de "agricultura por contrato" (AC), la cual ha sido oficialmente definida como "la operación mediante la cual el productor vende al comprador antes de cosechar su producto, a través de la celebración de contratos de compra-venta, bajo condiciones específicas de volumen, calidad, tiempo, lugar de entrega, precio y condiciones de pago" (SAGARPA, 2002). La mayoría de los contratos se firman entre organizaciones de productores y compradores de granos, y son revisados y avalados por ASERCA (Apoyos y Servicios a la Comercialización Agropecuaria), institución perteneciente a la SAGARPA (Secretaría de Agricultura, Desarrollo Rural, Pesca y Alimentación). En ellos se establece el llamado "precio de contrato", vinculado al precio de futuro del grano en la Bolsa de Futuros de Chicago (CBOT) existente al momento del registro del contrato. Para los productores, dicho precio constituye el mínimo a recibir (precio "piso"), pudiendo acceder a uno mayor si ocurren posteriores incrementos en las cotizaciones internacionales, mientras que para los compradores constituye el precio máximo a pagar (precio "techo"), siendo posible pagar posteriormente uno menor, en caso de que descienda el precio internacional del grano. Otra regla de la AC es que el grano de los productores debe ser pagado al tipo de cambio establecido por el Banco de México ("Fix"), vigente al momento de la entrega del grano a los compradores.

Sin embargo, para acceder a la protección ante futuras variaciones de los precios de los granos hay que comprar en CBOT ciertos instrumentos financieros denominados " $\mathrm{CO}$ berturas de precios" las cuales tienen un costo ("primas"). Desde que empezó a funcionar el programa de AC, el gobierno ha subsidiado distintos porcentajes de las primas a los participantes (productores y compradores de granos), fluctuando actualmente entre 45\% y 100\% de su costo. El dinamismo que ha tenido el programa de AC en los últimos años se refleja tanto en el crecimiento del volumen de productos apoyados con "coberturas de precios" (de 6.3 a 13.3 millones de toneladas en 2005-2013), como en el del presupuesto que se le ha asignado (de 497 a 6.4 millones de pesos mexicanos) (ASERCA, 2014). Los productos subsidiados han sido mayoritariamente granos (el 38\% de la producción doméstica), siendo el principal el maíz, cuyo volumen representó la mitad del total apoyado, seguido por trigo (26\%) y sorgo (20\%). En 2014, se apoyaron 4.5 millones de toneladas de maíz bajo AC, de las cuales el 60\% correspondió a maíz blanco (2.7 millones de toneladas) y 40\% a maíz amarillo (1.8 millones de toneladas) (Pérez, 2014). 


\section{La gran dependencia de México: maíz amarillo para el sector pecuario}

A pesar de que durante 2013/14 México fue, por sus volúmenes, el octavo productor mundial de maíz, ocupó el tercer sitio como importador, antecedido por Japón y la Unión Europea. Esto, debido a la dimensión de su consumo doméstico, en el cual México se sitúa en el quinto lugar, después de Estados Unidos, China, la Unión Europea y Brasil (USDA, 2014). En 2013, el consumo total de maíz en México fue de 27.4 millones de toneladas, el 43\% de las cuales se destinaron a la elaboración de tortillas, un alimento básico de la población, mientras que un 35\% se destinó al consumo animal. El restante porcentaje se utilizó en las industrias de almidones y derivados, de cereales y botanas, y para la producción de semillas (Tabla 1). El maíz para elaborar tortillas (11.9 millones de toneladas anuales) se conforma mayoritariamente por maíz blanco, mientras que el consumo del sector pecuario ( 9.9 millones de toneladas) se integra principalmente por maíz amarillo forrajero (75\%) y, el restante porcentaje, por otras variedades de maíz (blancos híbridos y diversos criollos). Por su parte, las industrias anteriormente señaladas utilizan exclusivamente maíz amarillo.

Tabla 1. México: oferta y consumo de maíz (2013)

\begin{tabular}{|l|c|c|c|}
\hline & $\begin{array}{c}\text { Miles } \\
\text { toneladas }\end{array}$ & $\begin{array}{c}\text { Oferta total } \\
(\%)\end{array}$ & $\begin{array}{c}\text { Consumo total } \\
(\%)\end{array}$ \\
\hline Oferta maíz blanco* $^{*}$ & 17,502 & 64 & - \\
Oferta maíz amarillo (uso pecuario)** $^{*}$ & 9,988 & 36 & - \\
Oferta total & 27,490 & 100 & - \\
Consumo (tortillas principalmente) & 11,900 & - & 83 \\
Consumo industria almidonera & 2,200 & - & 2 \\
Consumo industria cereales y botanas & 500 & - & 11 \\
Semillas para siembra & 2,902 & & 36 \\
Consumo animal & 9,988 & - & 100 \\
\hline Consumo total & 27,490 & - & 8 \\
\hline
\end{tabular}

* Se incluyen las variedades criollas, incluyendo las de color.

** Se conforma por maíz amarillo forrajero y otras variedades (7.3 y 2.4 millones de toneladas, respectivamente).

Fuente: Elaborado con datos de ANFACA, 2014 y SAGARPA, 2015.

La producción doméstica de maíz durante los últimos años (2005-13) ha promediado 21 millones de toneladas, de las cuales la gran mayoría han sido de maíz blanco híbrido y variedades criollas, y solo un 10\% de amarillo forrajero (SAGARPA, 2015). La producción de los dos primeros tipos de maíz le han garantizado a México una tradi- 
cional autosuficiencia que le ha permitido cubrir el consumo doméstico. Por tanto, la dependencia de ese país ha sido y sigue siendo de maíz amarillo (destinado mayoritariamente al sector pecuario), cuyo creciente déficit se ha cubierto tradicionalmente con importaciones procedentes de Estados Unidos, ya que la producción doméstica de ese grano (2.2 millones de toneladas en 2013) solo aporta la quinta parte del consumo nacional, el cual es del orden de 10 millones de toneladas. Dichas importaciones promediaron 8.2 millones de toneladas anuales durante 2005-13 (Tabla 2), haciendo cada vez más costosa la creciente dependencia alimentaria de México, en el contexto de las alzas en los precios internacionales de los granos que se han dado en los últimos años. Esta creciente dependencia no solo ha sido efecto de la política agrícola, sino también de la expansión del consumo de los alimentos que utilizan el maíz amarillo como insumo, es decir, los productos pecuarios (carnes, leche, huevo y derivados), tema que desarrollaremos a continuación.

Tabla 2. México: producción e importaciones de maíz (2000-2014)

\begin{tabular}{|c|c|c|c|c|c|}
\hline Años & $\begin{array}{c}\text { Superficie } \\
\text { Cosechada } \\
\text { (ha) }\end{array}$ & $\begin{array}{c}\text { Volumen } \\
\text { Producción } \\
\text { (ton) }\end{array}$ & $\begin{array}{c}\text { Importaciones } \\
\text { (ton)** }\end{array}$ & $\begin{array}{c}\text { Importaciones } \\
\text { maíz amarillo } \\
\text { (ton)* }\end{array}$ & $\begin{array}{c}\text { Importaciones } \\
\text { maíz blanco } \\
\text { (miles ton)* }\end{array}$ \\
\hline 2000 & $7,133,181$ & $17,556,905$ & $5,172,796$ & $5,172,796$ & 0 \\
2001 & $7,812,848$ & $20,134,312$ & $5,842,149$ & $5,841,660$ & 0 \\
2002 & $7,120,920$ & $19,297,755$ & $6,314,754$ & $6,314,109$ & 0 \\
2003 & $7,522,921$ & $20,701,420$ & $7,685,807$ & $7,685,512$ & 0 \\
2004 & $7,698,426$ & $21,685,833$ & $7,478,336$ & $7,477,990$ & 0 \\
2005 & $6,607,619$ & $19,338,713$ & $8,521,975$ & $8,521,909$ & 12 \\
2006 & $7,296,848$ & $21,893,209$ & $10,691,683$ & $10,691,420$ & 148 \\
2007 & $7,206,201$ & $22,592,588$ & $10,964,213$ & $10,963,966$ & 218 \\
2008 & $7,197,744$ & $23,376,689$ & $8,989,857$ & $8,989,512$ & 345 \\
2009 & $6,060,279$ & $18,892,521$ & $7,145,768$ & $7,145,576$ & 192 \\
2010 & $6,960,193$ & $21,759,800$ & $7,631,190$ & $7,630,686$ & 440 \\
2011 & $6,069,301$ & $17,635,417$ & $9,854,706$ & $8,388,089$ & 470 \\
2012 & $6,923,899$ & $22,069,254$ & $8,475,746$ & $8,475,352$ & 394 \\
2013 & $7,095,630$ & $22,663,953$ & $6,537,683$ & $6,537,580$ & 103 \\
2014 & n.d. & n.d. & $10,336,679$ & $10,336,157$ & 522 \\
\hline
\end{tabular}

* Son las procedentes de Estados Unidos.

Fuente: USDA, 2015 y SAGARPA, 2015. 


\section{Producción de alimentos animales y su demanda de granos}

El sector productor de alimentos animales ubicado en México ha tenido un comportamiento muy dinámico, en respuesta al incremento en el consumo doméstico de carnes, lácteos y huevo, producto éste en el que México es el principal consumidor mundial (UNA, 2012). En 2011, la producción mexicana de alimentos animales fue de 28.3 millones de toneladas, de las cuales el 52\% se destinó a la avicultura, un 26\% a los bovinos (carne y leche), 15\% a la porcicultura y el restante 7\% a otras especies (acuacultura, mascotas, conejos, caballos, etc.) (SAGARPA, 2012a).

La expansión de la industria de alimentos animales ha implicado una creciente demanda de granos: en 2011, por ejemplo, consumió 19.7 millones de toneladas de esos bienes, la mitad de los cuales procedió del exterior. Los principales granos consumidos fueron los siguientes: maíz (9.7 millones de toneladas); sorgo (8.9 millones de toneladas) y otros granos forrajeros (trigo, cebada y avena) (1.1 millones de toneladas). Además, se requirieron pastas oleaginosas (soya y canola) ( 6 millones de toneladas) y otros insumos (subproductos de trigo, maíz, vitaminas, minerales y aceites) (4.3 millones de toneladas) (SAGARPA, 2012a; ANFACA, 2014). Dado que la gran mayoría del maíz utilizado en la elaboración de alimentos animales es amarillo, es este sector productivo el principal consumidor de este grano y, por tanto, el principal importador. Le sigue en importancia la industria de almidones, que también produce ciertos derivados (fructuosa, dextrosa, colorantes, aceites comestibles, etc.), y los fabricantes de cereales y botanas (Tabla 1).

Como ya señalamos, la industria de almidones consume solo maíz amarillo, dadas las características de los productos que fabrica. La situación es distinta para los pecuarios o elaboradores de alimentos animales, ya que ellos sí pueden sustituir en cierta medida la composición de los granos que utilizan (sobre todo entre sorgo y maíz), en función tanto de sus precios como de los apoyos gubernamentales. Estos se han otorgado a través de los ya mencionados programas de "agricultura por contrato" (AC) y "coberturas de precios” (CP), cuyas características y funcionamiento serán reseñados a continuación.

\section{El maíz de los valles altos de Puebla}

Puebla, origen del maíz, ha ocupado en diversos años el octavo lugar como productor de ese grano en México. La producción anual de ese estado es muy cambiante, ya que el maíz se produce mayoritariamente en secano (solo el 9\% de la superficie cosechada es irrigada), y el cultivo está sujeto a sequías y heladas ${ }^{1}$. Cuando estos eventos no son

1. En 2009, por ejemplo, una severa sequía ocasionó la pérdida del 37\% de la siembra de maíz (SAGARPA, 2012b). 
relevantes, Puebla produce alrededor de 1 millón de toneladas anuales de maíz (SAGARPA, 2015), las cuales son cultivadas mayoritariamente por productores minifundistas (menos de 5 hectáreas), los cuales conforman el 85\% de las unidades de producción.

De las siete regiones socio-económicas en que se ha dividido a Puebla (INAFED, 2015), la más importante como productora de maíz es la región III Ciudad Serdán, y de la cual ha procedido la mayoría del maíz que se ha comercializado bajo los programas estudiados (Figura 1). Esta región se conforma por 24 municipios ubicados en el centro-oriente del estado, los cuales aportaron 244 mil toneladas de maíz en 2012, es decir, casi la cuarta parte del volumen cosechado en la entidad. Los tres municipios más relevantes (Tlachichuca, Chalchicomula de Sesma y San Salvador El Seco) aportan casi la mitad de la producción de la región. En ésta, el maíz y otros cultivos se siembran en los llamados "valles altos", como son los llanos de San Andrés, conocidos también como Valle de Serdán, y los llanos de San Juan, ambos a altitudes que fluctúan entre 1,800 y 3,200 msnm, localizados en las estribaciones del Pico de Orizaba, la montaña más alta de México. La región III presenta diversos climas, predominando el templado sub-húmedo y el clima frío, con temperaturas promedio mensuales de entre 10 y 15 grados centígrados y presencia de heladas desde mediados de septiembre hasta mediados de marzo, con una media de 70 heladas por año (Ramírez et al. 1998).

Los pocos productores de la región que cuentan con riego extraen el agua de pozos profundos, y son los que siembran maíz híbrido, el cual requiere de este recurso para poder solventar de mejor manera los eventos climáticos que amenazan a los valles altos, aunque es muy común que también cultiven variedades criollas (azul o morado, amarillo y blanco). Algunos siembran hortalizas (zanahoria, papa, haba, lechuga, cilantro y coliflor) después de concluido el ciclo productivo del maíz, llegando a obtener hasta tres cosechas de cultivos al año. Por su parte, entre los productores de secano, que conforman la gran mayoría, se acostumbra cultivar maíz en la misma parcela durante dos años y al siguiente sembrar haba, frijol o calabaza, pues consideran que solo así puede mantenerse la calidad de los suelos. Siembran variedades criollas de maíz, predominando los llamados criollos mejorados, los cuales resisten mejor la sequía, aunque tienen menores rendimientos que los híbridos, dado que los primeros solo dan una mazorca, mientras que los híbridos dan dos. Entre los criollos prevalece el "blanco cremoso", que sirve tanto para la elaboración de tortillas (nixtamal) como para alimento animal. La mayoría de este maíz corresponde a la variedad "chalqueño mejorado", llamado así porque su semilla la trajeron de Chalco, Estado de México, y cuyos rendimientos promedio son de 3-4 ton/ha. Le sigue en importancia el criollo amarillo y, en mucho menor medida, los azules y rosados, utilizados también en la elaboración de tintes.

La prevalencia de maíces criollos no solo caracteriza a la región III, sino a Puebla en general, para la cual se ha calculado que dichas variedades conforman entre 80-85\% de su producción (Espinosa, 2012, entrevista directa). El maíz del estado se cultiva en el ciclo primavera-verano, sembrándose en marzo-mayo y cosechándose en diciembre- 


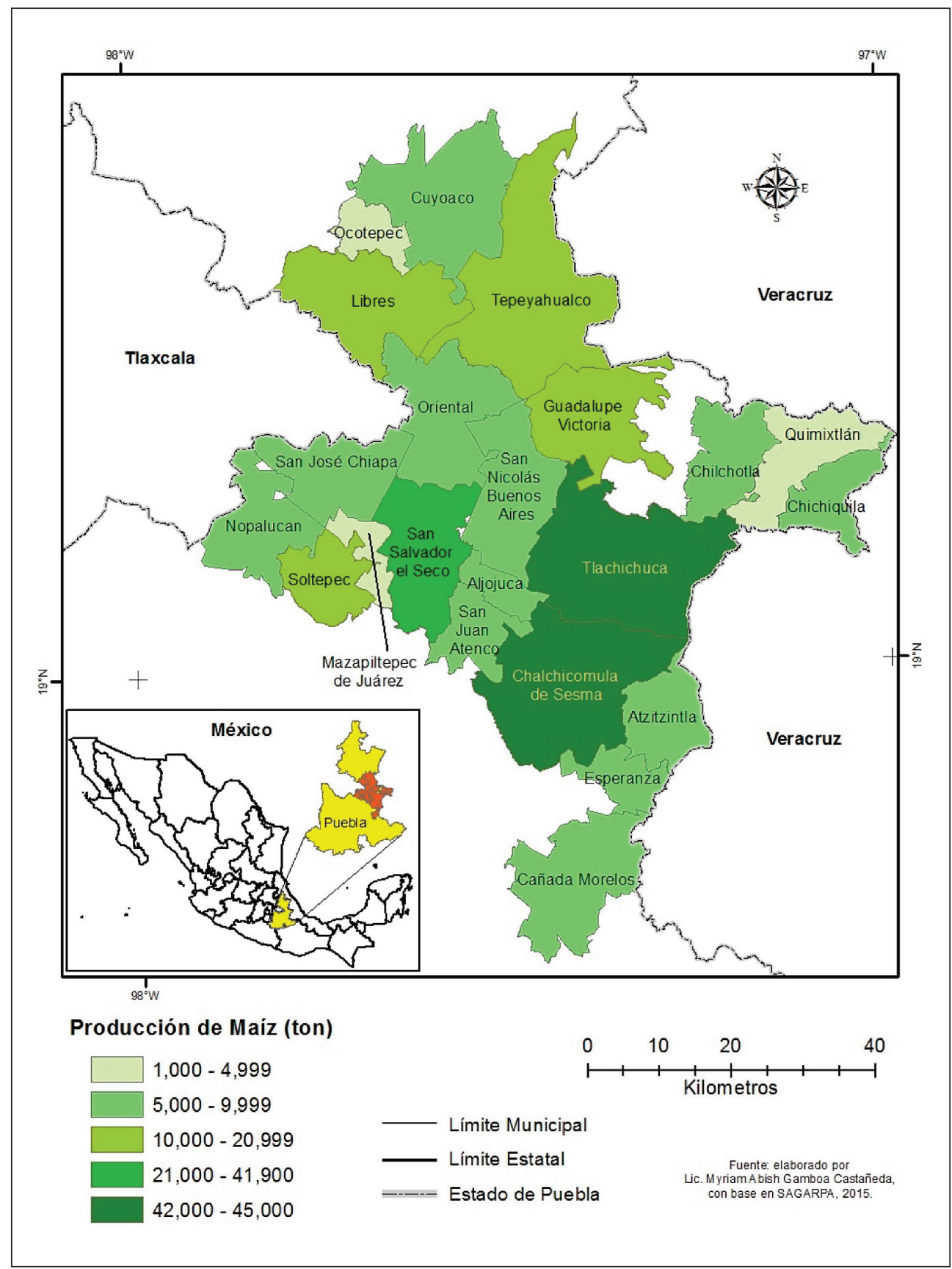

Figura 1. Municipios productores de maíz en la región III Ciudad Serdán (2012). 
febrero. Prevalece su uso integral (grano y rastrojo), tanto para consumo humano como animal (Viveros, 2010), ya que los productores combinan la agricultura con la cría de animales a diversas escalas, sobre todo vacas para ordeña, becerros de engorda y ovinos, para lo cual muchos de ellos también cultivan alfalfa. Esta combinación es una estrategia de sobrevivencia de los productores, ya que, como señaló uno de ellos.... de no ser así, de la agricultura no se viviría (Zacaula, 2012, entrevista directa). El maíz que se comercializa se vende a productores de tortillas, pecuarios (avicultores y/o porcicultores), coyotes regionales y de otros estados (Ej. Oaxaca) y a "semilleros", quienes se ubican en mercados abiertos, como el que semanalmente se pone en Ciudad Serdán.

Sin embargo, Puebla es deficitaria en maíz, ya que requiere 1.3 millones de toneladas anuales para el consumo humano, aunado a lo que demanda su sector pecuario, por lo que tiene que traerse ese grano de otros estados como Sinaloa, la zona del Bají y Veracruz. En el siguiente apartado nos referiremos concretamente al maíz poblano que se dirige al sector pecuario de la entidad, ya que solo dicho grano ha sido apoyado por los programas gubernamentales ya reseñados.

\section{El maíz bajo contrato y las empresas pecuarias de Tehuacán}

Las empresas dedicadas a la avicultura y/o porcicultura en Puebla se ubican en la zona de Tehuacán, y su relevancia ha posicionado a esa entidad como la segunda productora de huevo a nivel nacional, tercera en carne de cerdo y quinta en carne de pollo (UNA, 2012; SAGARPA, 2012c). Utilizan el maíz para la elaboración de alimentos animales, siendo las consumidoras más relevantes las empresas integradas, es decir, las que fabrican dichos alimentos para su autoconsumo, siguiendo en importancia las no integradas, que son las que los producen solo para su venta a terceros (ej. Agribrands Purina y Agro Tehuacán). De acuerdo al presidente de la Asociación de Avicultores de Tehuacán, el sector pecuario poblano consume un millón de toneladas anuales de granos (principalmente sorgo y maíz), el 90\% de los cuales es importado de Estados Unidos, dado que en México no existe el volumen que ellos requieren (García de la Cadena, 2011, entrevista directa). Dicho sector compra un promedio de 70,000 toneladas anuales de maíz producido en Puebla, que es de variedades criollas (blanco cremoso y, en menor medida, amarillo), mientras que sus importaciones son de maíz amarillo forrajero (Espinosa, 2011, entrevista directa).

El programa de AC se empezó a expandir en Puebla a partir de 2002. Para 2008 se firmaron contratos por 50,000 toneladas de maíz; en 2010, por 46,610 toneladas y en 2011 por 27,000 toneladas (ASERCA, 2012a). En 2009, el maíz comercializado fue mínimo debido a la ya mencionada sequía que abatió al estado. Las empresas pecuarias se inscribieron en el programa AC debido a que el gobierno les condicionaba los cupos de importación de maíz a tener contratada con productores domésticos cierta can- 
tidad de sus requerimientos de ese grano (García de la Cadena, 2011). Esta condicionante dejó de funcionar a partir de 2008, en que se da la libre importación de bienes agropecuarios, como efecto del TLCAN. Desde entonces, dichas firmas han encontrado ventajas para seguir participando voluntariamente en el programa, siendo las más relevantes compradoras de maíz las que integran el consorcio o grupo Romero. Este, el más importante de Puebla en el ramo avícola y porcícola, lo inició en 1948 Socorro Romero Sánchez, pero después algunos de sus familiares se incorporaron a la actividad, dividiéndose entre ellos las empresas existentes y creando otras nuevas. Actualmente, el grupo Romero se integra por las siguientes firmas que, de acuerdo a su propia información, se manejan de manera independiente entre sí: El Calvario, Socorro Romero, Estela Romero Bringas, Mercedes Romero Bringas y PATSA (Productos Agropecuarios de Tehuacán SA de CV). En 2010, estas empresas adquirieron el 65\% del maíz que ingresó al programa AC, habiendo sido la firma Socorro Romero la principal compradora (Tabla 3). Esta empresa en particular es la segunda productora de huevo de Puebla, y la más relevante dentro del ramo porcícola, vendiendo animales en vivo y procesados. En carne de puerco, esta empresa ocupa el sexto lugar a nivel nacional (antecedida por firmas como Granjas Carroll, GENA y Soles), teniendo sus 40 granjas porcícolas tanto en Puebla como en el estado de Oaxaca (Huerta, 2012, entrevista directa). Abastecen de carne de puerco y huevo al centro y sureste de México.

Tabla 3. Puebla: compradores del maíz bajo agricultura por contrato (2010)

\begin{tabular}{|l|c|}
\hline Comprador & Toneladas \\
\hline Socorro Romero Sánchez (Avícola Tehuacán) & 8,890 \\
Productos Avícolas El Calvario & 8,763 \\
Productos Agropecuarios de Tehuacán (PATSA) & 8,636 \\
Estela Romero Bringas (Vega de Pas) & 2,667 \\
Haycer SA de CV & 2,540 \\
Porcina La Bellota SA de CV & 1,524 \\
Avicultores Unidos del Valle de Tehuacán (PABSA) & 1,270 \\
Mercedes Romero Bringas (Mr. Egg) & 1,270 \\
Otros* & 11,050 \\
\hline Total estatal & $\mathbf{4 6 , 6 1 0}$ \\
\hline
\end{tabular}

* Granjas Carroll, avicultores de Veracruz, etc.

Fuente: ASERCA, 2012a.

La empresa Socorro Romero fabrica sus propios alimentos animales (300,000 toneladas anuales), el 60\% de los cuales es para aves y el $40 \%$ para cerdos, contando con una capacidad de almacenamiento de 46,000 toneladas de granos. En la elaboración de 
dichos alimentos se utilizan mayoritariamente granos (en un 80\%), pero también los llamados subproductos (grasas, minerales, vitaminas, etc.). Su consumo anual de granos es del orden de 200,000 toneladas (maíz y sorgo, fundamentalmente), el 90\% de los cuales es importado y el restante 10\% adquirido en México. Por razones de logística, los granos importados son comprados a través de Cargill y ADM (Archer Daniels Midland), ingresando a México por el puerto de Veracruz, desde donde se trasportan por tren hasta arribar a las instalaciones de la empresa (Huerta, 2012, entrevista directa). Sus directivos señalan que el maíz estadounidense es de menor calidad que el doméstico, ya que contiene más micotoxinas y hongos, por lo que tienen que aplicarle fungicidas, siendo además menos fresco. Es interesante señalar que tanto en esta firma como en muchas

Tabla 4. México: empresas líderes de aves ponedoras (2012)

\begin{tabular}{|c|c|c|c|}
\hline Compañia & Ciudad & $\begin{array}{l}\text { Gerente } \\
\text { General }\end{array}$ & $\begin{array}{c}\text { No. Ponedoras } \\
\text { en producción } \\
\text { (miles) }\end{array}$ \\
\hline Proteína Animal (PROAN) & San Juan de los Lagos, Jal. & Manuel Romo & 25,200 \\
\hline Bachoco SA & Ciudad Obregón, Son. & Rodolfo Ramos & 11,100 \\
\hline El Calvario & Tehuacán, Pue. & Gustavo Romero & 8,800 \\
\hline Empresas Guadalupe & Guadalajara, Jal. & Benjamín Pérez & 7,470 \\
\hline Rancho Grande & Cd. Obregón, Son. & Germán Tapia & 5,000 \\
\hline $\begin{array}{l}\text { Socorro Romero } \\
\text { (Avícola Tehuacán) }\end{array}$ & Tehuacán, Pue. & $\begin{array}{l}\text { Miguel Angel } \\
\text { Celis Romero }\end{array}$ & 3,600 \\
\hline José Asunción & San Juan de los Lagos, Jal. & $\mathrm{N} / \mathrm{D}$ & 3,100 \\
\hline Estela Romero Bringas & Tehuacán, Pue. & $\mathrm{N} / \mathrm{D}$ & 2,900 \\
\hline $\begin{array}{l}\text { Productora de } \\
\text { Huevo Gigantes }\end{array}$ & Tepatitlán, Jal. & Bertha González & 2,600 \\
\hline Imp. Agropec. Sta. Rosa & San Juan de los Lagos, Jal. & $\mathrm{N} / \mathrm{D}$ & 2,500 \\
\hline $\begin{array}{l}\text { Avícola González } \\
\text { y González }\end{array}$ & Tepatitlán, Jal. & Toribio González & 2,490 \\
\hline Gena Agropecuaria & Acatic, Jal. & Carlos Ramírez & 2,400 \\
\hline $\begin{array}{l}\text { Mercedes Romero } \\
\text { Bringas }\end{array}$ & Tehuacán, Pue & $\mathrm{N} / \mathrm{D}$ & 2,070 \\
\hline Sanfandila & Lagos de Moreno, Jal. & Juan José Vega & 2,070 \\
\hline Subtotal & & & 81,300 \\
\hline Otras (10 firmas) & & & 64,356 \\
\hline \multicolumn{3}{|l|}{ Total nacional* } & 180,782 \\
\hline
\end{tabular}

* Se incluyen los dos ciclos anuales.

Fuente: Industria Avícola, 2012 y USDA, 2012b. 
otras que elaboran alimentos animales la tendencia es a incorporar cada vez más "subproductos" en vez de granos, debido a los crecientes precios internacionales de éstos.

El segundo comprador en importancia es la firma El Calvario, principal productor estatal de huevo ( 8.8 millones de aves de postura) y relevante productor de alimentos animales (360,000 toneladas anuales). En el primer producto dicha empresa ocupa el tercer sitio a nivel nacional, pero considerando al conjunto de firmas que conforman el consorcio Romero, sus inventarios de aves ponedoras (17.3 millones en 2012) lo llevan al segundo lugar como productor de huevo en México, antecedido por la firma PROAN (Proteína Animal o Huevos San Juan) (25.2 millones de aves ponedoras), y seguido por Bachoco (11 millones) (Tabla 4). Este sector productivo se caracteriza por un alto grado de concentración, ya que las 14 mayores empresas concentran el 56\% del inventario nacional de aves ponedoras (Industria Avícola, 2012).

El tercer comprador de maíz es otra firma del consorcio Romero, Productos Agropecuarios de Tehuacán (PATSA), que desde hace 21 años se dedica a la producción y comercialización de pollo de engorda (venta de carne de pollo y, en menor medida, de aves en pie), con granjas en Puebla y Oaxaca. Ocupa el sexto sitio en este ramo a nivel nacional (50 millones anuales de pollos de engorda), antecedida por Bachoco, Pilgrim's Pride, Tyson, Grupo Pecuario San Antonio y Avigrupo (Tabla 5).

Entre el resto de los compradores de maíz bajo contrato figura PABSA que, junto con Agribrands Purina y Agro Tehuacán constituyen las empresas no integradas más relevantes como productoras de alimentos animales de Puebla. Agribrands Purina, perteneciente al consorcio estadounidense Cargill, dedica la producción de su planta de Tehuacán a abastecer tanto en Puebla como en otros estados (Veracruz, Tlaxcala, Oaxaca y Chiapas), a engordadores de bovinos, avicultores (pollo de engorda y aves de postura) y porcicultores. Empezó a participar en el programa AC para poder acceder a los cupos de importación de maíz y continuó haciéndolo mientras incorporaba granos a sus productos finales, sin embargo, desde hace años solo fabrica en sus instalaciones de Tehuacán subproductos (pre mezclas), debido al creciente precio de los granos. Los subproductos contienen diversos elementos (vitaminas, minerales, aminoácidos, antibióticos, etc.) que los compradores mezclan con granos para lograr una dieta balanceada y cuidar la salud de los animales (Mendoza, 2012, entrevista directa).

\section{El maíz bajo contrato en Puebla: funcionamiento y vulnerabilidades}

La mayoría de los productores poblanos que han ingresado al programa de AC han vendido su maíz a través de la firma comercializadora Sinergia SA de CV (Servicios Integrales Agropecuarios de Productores de Maíz), perteneciente a la Confederación Nacional Campesina (CNC). En 2010, por ejemplo, a través de Sinergia se comercializó el 
Tabla 5. México: empresas líderes de pollos de engorda (2012)

\begin{tabular}{|l|l|c|}
\hline Compañia & Ciudad & $\begin{array}{c}\text { No. Pollos } \\
\text { por año (miles) }\end{array}$ \\
\hline Bachoco SA & Ciudad Obregón, Son. & 503,000 \\
Pilgrim's Pride de México & Querétaro & 184,000 \\
Tyson de México & Gómez Palacio, Dgo. & 157,000 \\
Grupo Agropecuario San Antonio & Córdoba, Ver. & 66,500 \\
Avigrupo & Temixco, Mor. & 61,000 \\
PATSA & Tehuacán, Pue. & 50,000 \\
Buenaventura & Villaflores, CHIS. & 41,000 \\
Pollos de Querétaro & Querétaro & 32,500 \\
Interpec San Marcos & Aguascalientes & 31,300 \\
Pollo Industrial de México & Mérida, Yuc. & 27,000 \\
Alcer Alimentos & Chimalhuacán & 22,000 \\
Grupo Avimarca & Tuxtla Gutiérrez, Chis. & 21,600 \\
Agroindustrias Quesada & Aguascalientes & 20,500 \\
Subotal & & $1,217,400$ \\
Otras firmas & & 241,545 \\
\hline Total nacional* & $\mathbf{1 , 4 5 8 , 9 4 5}$ \\
\hline
\end{tabular}

* Se incluyen los 5.4 ciclos de producción al año.

Fuente: Industria Avícola, 2012 y USDA, 2012.

90\% del maíz que ingresó a dicho programa, es decir, 42,000 toneladas. Esta organización, que se dedica solo a la comercialización de dicho grano, empezó a funcionar en 1994 y, en 2011, contaba ya con 19,700 socios. Ha logrado un nivel de capitalización considerable, contando con una Parafinanciera, Comercializadora, Fondo de Auto-aseguramiento, tres centros de acopio de grano, un parque de maquinaria, bodegas para distribuir fertilizante entre sus socios, transporte propio y un grupo de agrónomos que dan asesoría técnica a los productores (Salazar, 2011 y Zacaula, 2012, entrevistas directas).

Los dirigentes de Sinergia indicaron que la maquinaria la alquilan a sus socios a menor precio que la competencia y que los productores también adquieren el fertilizante más barato mediante compras consolidadas. Diversos productores entrevistados lo confirmaron, señalando que la organización les entrega los fertilizantes a crédito, con una tasa de interés mensual de 3\%. Para recoger estos insumos, los productores se agrupan para repartir conjuntamente el costo del transporte. 
Sinergia es quien firma los contratos de compra-venta con las empresas pecuarias de Puebla, evitando así que aquellas tengan que acordar con numerosos productores dispersos, los cuales carecen de organizaciones consolidadas e infraestructura de acopio de granos. También lleva a cabo ante ASERCA los trámites necesarios para acceder al programa de AC y recibe tanto los pagos hechos a los productores por el grano entregado, como algunos de los subsidios dados por el gobierno. En 2002, y de acuerdo a dirigentes de Sinergia, ésta solo había conseguido que dos productores entraran a AC, pero la continua labor de convencimiento entre ellos logró que para 2010 participasen 8,000 productores (Salazar, 2011). La gran mayoría de ellos fueron pequeños productores que cultivaban entre 1 y 5 hectáreas, aunque también participaron grandes productores de 50 hectáreas o más, ubicados en la región III Ciudad Serdán.

El grano cosechado no es almacenado en bodegas, sino que se va "libre a bordo", es decir, de la parcela hasta las plantas avícolas y/o porcícolas de Tehuacán, siendo los productores los que pagan el transporte del grano. Algunos de ellos señalaron que para participar en el programa tienen que irse a anotar a las oficinas del comisariado ejidal, especificando la superficie y volumen de maíz con los que van a participar. Posteriormente, también firman un acuerdo o contrato con Sinergia, a manera de compromiso escrito de entregar el grano acordado con ciertos requisitos de calidad.

Los resultados del programa estudiado durante los últimos años han sido los siguientes: en 2008 se comercializó, o sea, llegó a las bodegas de los pecuarios de Puebla, la mayoría del volumen de maíz que fue registrado ante ASERCA. En ese año, en que prevalecían los altos precios internacionales de 2007-2008, participar en el programa fue ventajoso para los productores, ya que el precio promedio al que vendieron su maíz fue de $\$ 4.60$ por kilo (puesto en Tehuacán), mientras que los intermediarios pagaban localmente a \$2.50 por kilo. Sin embargo, durante 2008 ocurrió un drástico proceso de devaluación del peso mexicano frente al dólar estadounidense, que llevó el tipo de cambio de 12.50 a 15 pesos mexicanos por USD al momento de entrega de las cosechas. De acuerdo a los contratos, las empresas compradoras deben pagar el grano al tipo de cambio vigente, no obstante lo cual ofrecieron a los productores comprar su grano solamente a la paridad de $\$ 13.50$ por USD. Ante la ausencia de otras alternativas de venta, los productores aceptaron la oferta y se realizaron modificaciones a los contratos con el aval gubernamental, situación que se repitió en todas las demás entidades que participaron en AC durante 2008 y parte de 2009 (véase Echánove, 2013b y 2009).

En 2009, como ya señalamos, se comercializó muy poco del grano contratado debido a la sequía. En 2010, de las 46,610 toneladas contratadas solo se entregaron a los pecuarios menos de la mitad (20,000 toneladas), pero en esta ocasión debido a que los productores desviaron la diferencia hacia el mercado libre, donde los precios eran mayores a los precios de contrato. Así, mientras que el maíz bajo contrato puesto en Tehuacán era pagado por las firmas pecuarias a \$3.20 el kilo, los intermediarios ofrecían localmente $\$ 2.90$ por kilo. Pero dado que el productor es quien paga el transporte de 
su grano hasta dicha ciudad, le resultó más redituable venderlo localmente. Además, y como señalaron diversos productores entrevistados, el envío terrestre es complicado para ellos porque el volumen de grano que cosechan individualmente no es suficiente para llenar un camión (22 toneladas de capacidad máxima), por lo que tienen que coordinarse con otros productores para conjuntar cosechas.

En 2011, el diferencial de precios fue aún mayor, ya que los precios de contrato fluctuaron entre $\$ 2.80$ y $\$ 3.20$ el kilo, mientras que en el mercado libre se ofrecía $\$ 4.00$ por kilo de maíz. Este elevado precio se debió al llamado "efecto Sinaloa", entidad en donde las heladas de febrero de 2011 ocasionaron el desplome de sus cosechas de maíz, situación de gran repercusión dado que dicho estado es el principal productor de México. Este hecho, aunado a que ASERCA modificó en ese año los lineamientos de operación del programa AC, requiriendo que los productores contribuyesen con el 5\% del costo de las primas (hasta entonces el gobierno había pagado el 100\%), ocasionó el desinterés de los agricultores por participar en el programa. Las reglas también cambiaron para las empresas compradoras, que ahora tenían que contribuir con el 30\% de dichas primas. Por ello, se redujo considerablemente su participación, dando por resultado que solo se haya contratado en ese 2011 un total de 27,000 toneladas de maíz en Puebla (García de la Cadena, 2011, entrevista directa).

Para 2012, ASERCA aumentó aún más el porcentaje que productores y compradores tenían que poner por concepto de primas; para los primeros fue $15 \% \mathrm{y}$, para empresas y comercializadoras, el 50\%. Esto disminuyó aún más el interés por participar en la AC, no solo en Puebla sino en el país en general. Para revertir esta situación, el gobierno implementó a partir de 2013 nuevos esquemas de "coberturas de precios" y disminuyó los porcentajes de contribución de los participantes, lo que ha vuelto a reavivar el interés en el programa.

Sin embargo, independientemente de que los productores de Puebla vendan bajo contrato o a intermediarios, el maíz que comercializa la mayoría de ellos (pequeños productores) proporciona ingresos que no son suficientes para la subsistencia de una familia. La gran mayoría de ellos tienen un costo de producción del maíz criollo que fluctúa entre \$6,500-\$7,000 por hectárea, dependiendo de diversos factores, entre los que destaca el grado en que se apliquen insumos químicos, como fertilizantes. Estos, aunque fluctúan al alza y a la baja, se han incrementado en los últimos años, dado que la urea se importa de Estados Unidos y de otros países. Otros insumos, como el diesel, es ahora más costoso que la gasolina, habiendo señalado diversos productores que se necesitan 3 kilos de maíz para comprar 1 litro de diesel. Haciendo números, en 2011 el precio máximo que los productores bajo contrato recibieron fue de $\$ 3,200$ por tonelada de maíz. Con los rendimientos promedio ( 3 ton/ha) y el mínimo de los costos de producción $(\$ 6,500$ por hectárea o $\$ 2,167$ por tonelada), la ganancia obtenida fue de $\$ 1,033$ por tonelada o $\$ 3,100$ por hectárea. Los minifundistas, que cuando mucho cultivan 5 hectáreas, obtienen entonces un ingreso anual derivado del maíz de \$15,500. 
Obviamente, los \$1,292 mensuales que dicho monto representa no da para mantener a una familia de 5 personas en promedio. Situación que no se modifica sustancialmente aún en el caso de los mayores precios pagados en 2011 en el mercado libre.

\section{Reflexiones finales}

A pesar de que Puebla es un productor y consumidor de maíz importante, no es de los estados más beneficiados por el programa de AC, en gran parte porque la industria productora de harina de maíz para la elaboración de tortillas, relevante comprador de la producción doméstica de maíz blanco y beneficiario importante de dicho programa, prefiere los maíces blancos híbridos a los criollos, ya que con los primeros obtienen mayores rendimientos en el proceso industrial (harina-tortillas). Por otra parte, los productores de Puebla son de secano, minifundistas, con muy bajos niveles de organización y capitalización, y sujetos a continuos desastres climáticos, lo que demuestra, de acuerdo a Key y Runsten (1999), que los efectos de la AC, tanto a nivel de productor como en el desarrollo rural, dependen en gran parte del tipo de productor involucrado.

Sin embargo, Puebla comparte las mismas ventajas y vulnerabilidades que el programa estudiado ha tenido a nivel nacional, y constituye un interesante ejemplo de cómo los maíces criollos de México, aptos para consumo humano, terminan en las fábricas que elaboran alimentos para animales, en gran parte debido a los apoyos o subsidios otorgados por el gobierno.

Entre las limitantes del programa de AC figura su complejidad, lo que lo hace poco comprensible para los productores, dificultando así la toma de decisiones independientes y oportunas. Para saber, por ejemplo, el momento adecuado para vender sus "coberturas de precios" en el mercado de futuros (en función de la tendencia de los precios), los pequeños productores tienen que contratar a despachos de asesoría, con la consiguiente erogación de recursos y no pocos desengaños. Son pocas las organizaciones de productores a nivel nacional que cuentan con personal capacitado en el manejo de instrumentos financieros y pertenecen, sobre todo, a grandes productores. Otro señalamiento de los participantes en AC es la excesiva burocracia por parte de ASERCA, que les impide tener la información necesaria antes de la siembra de los granos, así como el retraso en el pago de subsidios, comúnmente hasta por un año.

Es un hecho también que el programa estudiado es regresivo y se caracteriza por una concentración de los subsidios en pocos beneficiarios y regiones, al igual que ocurre con otros relevantes programas de apoyo a la agricultura (véase Fox y Haight, 2010; FUNDAR, 2015; Merino, 2010; Rello, 2008; Steffen, 2007). Tradicionalmente se ha beneficiado sobre todo a la región norte de México, que es donde se ubica la mayoría de los grandes y medianos productores. En el caso de la AC, por ejemplo, en 2012 el 
$72 \%$ de los beneficiarios de dicho programa se ubicó en esa zona (estados de Sinaloa, Tamaulipas, Sonora y Chihuahua) (Echánove, 2013b). Y es ese tipo de productores los que, por su escala y características (grandes extensiones de tierra con riego), pueden producir ciertos volúmenes mínimos de granos, al mismo tiempo que cuentan con organizaciones consolidadas (algunas con poder para cabildear los subsidios a nivel federal) y acceso a transporte y silos almacenadores de grano, elementos todos ellos que les permiten sacar mayores beneficios de la $\mathrm{AC}$. Sin embargo, es relevante señalar que el total de los productores beneficiados por dicho programa conforma un reducido número dentro del universo de los que cultivan granos en México (comerciales y de autoconsumo). En 2011, por ejemplo, se subsidió a 436,329 productores, que representaron tan solo el 11\% del mencionado universo (ASERCA, 2011).

Otros de los principales beneficiados de la AC son las grandes empresas consumidoras y/o comercializadoras de granos, que han recibido importantes subsidios del gobierno (véase LENCE, 2012), entre las que se incluyen las firmas avícolas y/o porcícolas de Puebla. El sector pecuario también ha sido favorecido en el caso de los principales estados productores de sorgo (Tamaulipas y Guanajuato) y de maíz amarillo (Chihuahua), como se ha demostrado en otros casos de estudio (Echánove 2009; 2013a; 2013b).

No obstante lo mencionado, es indudable que la AC ha aportado a los productores importantes ventajas, como las de tener un mercado asegurado y, en general, mayores ingresos que los que pudiesen obtener en el mercado libre, al igual que lo ocurrido en otros países en torno a diversos productos agrícolas (véase Brannstrom, 2000; Collins, 1993). En el caso del programa de AC, los productores también pueden conocer el precio de su grano de antemano (antes de las cosechas), y obtener subsidios gubernamentales. Y es que, como ciertos autores han señalado, los resultados en los productores de la "agricultura por contrato" dependen de las relaciones de poder entre éstos y las empresas, y varían de acuerdo a las estructuras agrarias y de mercado, y al entorno socioeconómico y político del país (Masakure y Henson, 2005; Porter y Philis-Howard, 1997).

Sin embargo, y esto no es exclusivo del caso de Puebla, entre los productores frecuentemente hay incumplimiento de los contratos, ya sea por causas ajenas a su voluntad (eventos climáticos), o debido a que los precios en el mercado libre son mayores a los de contrato, por lo que desvían su producción hacia el primero. Ello, por supuesto, significa un desperdicio de recursos federales aplicados a la compra de "coberturas de precios" para proteger granos que nunca se comercializaron bajo el programa. Pero también las empresas compradoras de esos bienes han incumplido los contratos ya firmados, debido a que el tipo de cambio vigente al momento de entrega de los granos no les favoreció.

Y es que las debilidades centrales de la AC radican en que dicho programa depende del comportamiento de factores tan variables como son los precios de los granos (internacionales y los vigentes en el mercado libre doméstico), y el tipo de cambio (peso 
mexicano-dólar estadounidense). En ese contexto, el programa beneficia a los productores solo cuando los precios de contrato son mayores a los del mercado libre (doméstico) y el tipo de cambio es estable.

El análisis de la AC nos revela la necesidad de replantear la política de subsidios a la agricultura implementada por el gobierno mexicano. Los elevados recursos dirigidos a dicho programa favorecerían a quien más lo necesita, como son los pequeños productores, si fuesen utilizados en otros apoyos hoy día insuficientes, como son el programa que establece un precio mínimo de venta de los granos (Ingreso Objetivo); los que les apoyan ante desastres naturales, y los que subsidian el crédito y el aseguramiento.

\section{Agradecimientos}

Agradezco el financiamiento para esta investigación por parte de CONACYT (Consejo Nacional de Ciencia y Tecnología) (proyecto 155376), así como las facilidades otorgadas durante una estancia sabática por la Universidad de Adelaide, Australia (Departamento de Historia de la Escuela de Humanidades), para la redacción final de este artículo. Igualmente, las valiosas observaciones de los evaluadores anónimos.

\section{Bibliografía}

ANFACA (Asociación Nacional de Fabricantes de Alimentos para el Consumo Animal, SC)., 2014. Anuario 2013.

Appendini, K., 2014. Reconstructing the Maize Market in Rural Mexico, Journal of Agrarian Change 14 (1), 1-25.

ASERCA (Apoyos y Servicios a la Comercialización Agropecuaria), 2011. Cobertura de precios de productos agropecuarios, Claridades Agropecuarias 220, 3-15.

ASERCA (Apoyos y Servicios a la Comercialización Agropecuaria), 2012a. Delegación Regional en Puebla. Estadísticas del programa de Agricultura por Contrato. Versión mimeográfica.

ASERCA (Apoyos y Servicios a la Comercialización Agropecuaria), 2012b. Coberturas de precios, patrón de participantes 2010. Disponible en: http://www.infoaserca.gob.mx (Consulta: 12.03.2013).

ASERCA (Agencia de Servicios a la Comercialización y Desarrollo de Mercados), 2014. Consulta Nacional de Coberturas por Estado. Disponible en: http://www.infoaserca.gob.mx/ (Consulta: 02.02.2015).

Bebbington, A., 2003. Global networks and local developments: agendas for development geography. Tijdschrift Economische en Sociale Geografie 94 (3), 297-309.

Brannstrom, C., 2000. Coffe labour regimes and deforestation on a Brazilian frontier, 1915-1965. Economic Geography 76, 326-346. 
CEPAL (Comisión Económica para América Latina y el Caribe), GTZ (Sociedad Alemana de Cooperación Técnica) y FAO (Organización de las Naciones Unidas para la Alimentación y Agricultura), 1998. Agroindustria y pequeña agricultura: vínculos, potencialidades y oportunidades comerciales. Santiago de Chile: Naciones Unidas.

Collins, J., 1993. Gender, Contracts and Wage Work: Agricultural Restructuring in Brazil's Sao Francisco Valley. Development and Change 24, 53-82.

Dolan, C., 2001. The 'Good Wife': Struggles over Resources in the Kenyan Horticultural Sector. The Journal of Development Studies 37 (3), 39-70.

Echánove, F., 2009. Políticas Públicas y Maíz en México: el Esquema de Agricultura por Contrato. Anales de Geografía 29 (2), 65-83.

Echánove, F., 2013a. Agricultural Policy and Feed Industry in Mexico. Mexican Studies 29 (1), 61-84.

Echánove, F., 2013b. Apoyos del gobierno a la comercialización de granos: los programas de agricultura por contrato y coberturas de precios. FUNDAR-Universidad de California Santa Cruz, ANEC-AMUCSS-CCMSs. Disponible en: http://subsidiosalcampo.org.mx (Consulta: 04.05.2014).

Fox, J. y Haight, L., 2010. Síntesis de los hallazgos: tendencias en la política de subsidios agrícolas. En Fox, J. y Haight, L. (coord.), Subsidios para la desigualdad. Las politicas públicas del maiz en México a partir del libre comercio. Dissa Impresores.

FUNDAR Centro de Análisis e Investigación, 2015. Disponible en: http://www.subsidiosalcampo. org.mx (Consulta: 05.05.2015).

Grossman, L., 1998. The Political Ecology of Bananas. Contract Farming, Peasants, and Agrarian Change in the Eastern Caribbean. Chapel Hill: University of North Carolina Press.

Gwynne, R., 2000. Contract Farming and Land Markets in Chile. Paper presented at the XXI International Congress of the Latin American Studies Association, Miami, March 16-18.

Gwynne, R., 2003. Transnational capitalism and local transformation in Chile. Tijdschrift Economische en Sociale Geografie 94 (3), 310-321.

INAFED (Instituto Nacional para el Federalismo y el Desarrollo Regional), 2015. Enciclopedia de los Municipios y Delegaciones de México. Disponible en: http://www.inafed.gob.mx/work/enciclopedia/EMM21puebla/regionalizacion.html (Consulta: 05.05.2015).

Industria Avícola., 2012. Empresas líderes 2012. Disponible en: http://www.industriaavicola-digital.com/industriaavicola/ (Consulta: 25.10.2013).

Key, N. y Runsten, D., 1999. Contract farming, smallholders and rural development in Latin America: the organization of agroprocessing firms and the scale of outgrower production. World Development 27 (2), 381-401.

Lawrence, G., 1999. Agri-Food Restructuring: A Synthesis of Recent Australian Research. Rural Sociology 64 (2), 186-202.

Lence, S., 2012. Market and Welfare Effects of Government Programs at Mitigating Crop Producers' Price Risks in Mexico. Reporte preparado para el Banco Interamericano de Desarrollo.

Little P. y Dolan, C., 2000. What It Means to Be Restructured: Nontraditional Commodities and Structural Adjustment in Sub-Saharan Africa. En: Commodities and Globalization. Anthropological Perspectives. A. Haugerud, M. Stone and P. Little, eds. Boston, USA: Rowman \& Littlefield Publishers, pp. 59-78. 
Masakure, O. y Henson, S., 2005. Why Do Small-Scale Producers Choose to Produce under Contract? Lessons from Nontraditional Vegetable Exports from Zimbabwe. World Development 33 (10), 1721-1733.

McKenna, M., Roche M., y Le Heron R., 1999. H.J. Heinz and Global Gardens: Creating Quality, Leveraging Localities. International Journal of Sociology of Agriculture and Food 8, 35-51.

Merino, M., 2010. Los programas de subsidios al campo: las razones y las sinrazones de una política mal diseñada. En: Fox, J. y Haight, L. (coord.), Subsidios para la desigualdad. Las políticas públicas del maíz en México a partir del libre comercio. Dissa Impresores.

Morvaridi, B., 1995. Contract Farming and Environmental Risk: The Case of Cyprus. Journal of Peasant Studies 23 (1), 30-45.

Pérez, M., 2014. Productores piden fijar en \$3,800 el precio de la tonelada de maíz. La Jornada, 3 de octubre. Disponible en: http://www.jornada.unam.mx/2014/10/03/politica/023n1pol (Cosulta: 11.11.2014).

Perry J. y Banker D., 2000. Contracting Changes How Farm Do Business. Rural Conditions and Trends 10, 50-56.

Porter, G. y Phillips-Howard, K., 1997. Comparing Contracts: An Evaluation of Contract Farming Schemes in Africa. World Development 25 (2), 227-238.

Raynolds, L., 1997. Restructuring National Agriculture, Agro-Food Trade and Agrarian Livelihoods in the Caribbean. En: Goodman, David J., y M. Watts (eds) Globalising Food. Agrarian Questions and Global Restructuring. London y New York: Routledge. Pp. 119-132.

Raynolds, L., 2000. Negotiating Contract Farming in the Dominican Republic. Human Organization 59 (4), 441-451.

Raynolds, L., 2002. Wages for Wives: Renegotiating Gender and Production Relations in Contract Farming in the Dominican Republic. World Development 30 (5), 783-798.

Rello, F., 2008. Inercia Estructural y Globalización: La Agricultura y los Campesinos Más Allá del TLCAN, Trabajo de discusión \#20. Washington y Massachusetts: Washington Office on Latin America and Global Development and Environment Institute.

SAGARPA (Secretaría de Agricultura, Ganadería, Desarrollo Rural, Pesca y Alimentación), 2002. Reglas de Operación del Programa de Apoyos Directos a la Comercialización y Desarrollo de Mercados. Diario Oficial de la Federación, 13 de marzo, pp. 41-50.

SAGARPA (Secretaría de Agricultura, Ganadería, Desarrollo Rural, Pesca y Alimentación), 2012a. Servicio de Información Agroalimentaria y Pesquera (SIAP). Resumen Nacional Pecuario. Disponible en: http://www.siap.sagarpa.gob.mx/ (Consulta: 08.09.2014).

SAGARPA (Secretaría de Agricultura, Ganadería, Desarrollo Rural, Pesca y Alimentación), 2012b. Situación actual y perspectivas del maíz en México 1996-2012. En: http://www.financierarural.gob.mx/informacionsectorrural/Documents/ (Consulta: 09.08.2014).

SAGARPA (Secretaría de Agricultura, Ganadería, Desarrollo Rural, Pesca y Alimentación), 2012c. Servicio de Información Agroalimentaria y Pesquera (SIAP) Resumen Nacional Pecuario. Disponible en: http://www.siap.sagarpa.gob.mx (Consulta: 06.07.2014). 
SAGARPA (Secretaría de Agricultura, Ganadería, Desarrollo Rural, Pesca y Alimentación), Sistema de Información Agroalimentaria y Pesquera, 2015. Disponible en: http://www.siap.gob.mx (Consulta: 03.04.2015).

Singh, S., 2003. Contract Farming in India: Impacts on Women and Child Workers. Gatekeeper Series no. 111. UK: International Institute for Environment and Development.

Steffen, C., 2007. La focalización de los subsidios a los granos en México. Polis 3 (2): 69,103.

Steffen, C. y Echánove, F, 2005. La sustitución del trigo por cebada en tierras ejidales de riego de Guanajuato, México: una alternativa efímera. Cuadernos Geográficos 37, 135-151.

UNA (Unión Nacional de Avicultores), 2012. Desempeño y Perspectivas de la Avicultura. En: http://www.una.org.mx (Consulta: 02.07.2013).

USDA (Departamento de Agricultura de Estados Unidos), Economic Research Service, 1997. Farmer s Use of Marketing and Production Contracts (AER-747).

USDA (Departamento de Agricultura de Estados Unidos), 2012a. Mexico. Poultry and Products Annual, Report \#MX2049. Disponible en: http://gain.fas.usda.gov/ (Consulta: 12.02.2014).

USDA (Departamento de Agricultura de Estados Unidos), 2012르. México. Grain and Feed Annual, Report \#MX2018. Disponible en: http://gain.fas.usda.gov (Consulta: 12.02.2014).

USDA (Departamento de Agricultura de Estados Unidos), 2012b. Grain: World Markets and Trade. Disponible en: http://www.fas.usda.gov/grain/Current (Consulta: 12.02.2014).

USDA (Departamento de Agricultura de Estados Unidos) (2014) Grain: World Market and Trade. Disponible en: http://apps.fas.usda.gov/psdonline/circulars/grain.pdf (Consulta: 12.02.2014).

USDA (Departamento de Agricultura de Estados Unidos), 2015. Global Agricultural Trade System Online. Disponible en: http://apps.fas.usda.gov/gats/default.aspx (Consulta: 12.02.2015).

Vellema, S., 1999. Agribusiness Control in Philippine Contract Farming: From Formality to Intervention. International Journal of Sociology of Agriculture and Food (8), 95-110.

Viveros, C., 2010. Estudio de la dinámica de aprovechamiento del maíz en las unidades de producción familiar en el Valle de Puebla, México. Tesis doctoral, Colegio de Posgraduados, Campus Puebla.

Watts, M., 1994. Life under Contract: Contract Farming, Agrarian Restructuring and Flexible Accumulation. En: P. Little y M. Watts (eds) Living under contract. Contract farming and agrarian transformation in Sub-Saharan Africa.. Madison, Wisconsin: The University of Wisconsin Press, pp. 21-77.

White, B., 1997. Agroindustry and Contract Farmers in Upland West Java. The Journal of Peasant Studies 24 (3), 100-136.

Yúñez, A., 2008. El TLCAN, las políticas públicas al sector rural y el maíz. Disponible en: http:// www.sebas12.com/centrotepoztlan/archivo/080209-A.pdf (Consulta: 09.05.2014). 


\section{Entrevistas citadas}

Espinosa, C., 2011. Representante en Puebla del Sistema Producto Maíz, entrevista directa, 15 de julio.

Espinosa, C., 2012. Representante en Puebla del Sistema Producto Maíz, entrevista directa, 6 de septiembre.

García de la Cadena, J., 2011. Presidente de la Asociación de Avicultores de Tehuacán, entrevista directa, 9 octubre.

Huerta, A., 2012. Gerente de la Empresa de Alimentos de Socorro Romero Sánchez, entrevista directa, 7 de julio.

Mendoza, E., 2012. Gerente de Planta de Agribrands Purina en Tehuacán, entrevista directa, 18 de agosto.

Salazar, A., 2011. Directivo de Sinergia, entrevista directa, 12 de mayo.

Zacaula, R., 2012. Productor de Ciudad Serdán, entrevista directa, 10 de junio. 